University of Nebraska - Lincoln

DigitalCommons@University of Nebraska-Lincoln

$11-1-2004$

\title{
Modeling the tertiary structure of a maize (Zea mays ssp. mays) non-symbiotic hemoglobin
}

\author{
Juán Sáenz-Rivera \\ Laboratorio de Biofísica y Biología Molecular, Facultad de Ciencias, Universidad Autónoma del Estado de \\ Morelos, Avenida Universidad 1001, Colonia Chamilpa, 62210 Cuernavaca, Morelos, Mexico \\ Gautam Sarath \\ University of Nebraska - Lincoln, Gautam.sarath@ars.usda.gov \\ Raul Peter-Arredondo \\ Laboratorio de Biofísica y Biología Molecular, Facultad de Ciencias, Universidad Autónoma del Estado de \\ Morelos, Avenida Universidad 1001, Colonia Chamilpa, 62210 Cuernavaca, Morelos, Mexico
}

Follow this and additional works at: https://digitalcommons.unl.edu/biochemistrysarath

Part of the Biochemistry, Biophysics, and Structural Biology Commons

Sáenz-Rivera, Juán; Sarath, Gautam; and Peter-Arredondo, Raul, "Modeling the tertiary structure of a maize (Zea mays ssp. mays) non-symbiotic hemoglobin" (2004). Gautam Sarath Publications. 5.

https://digitalcommons.unl.edu/biochemistrysarath/5

This Article is brought to you for free and open access by the Biochemistry, Department of at DigitalCommons@University of Nebraska - Lincoln. It has been accepted for inclusion in Gautam Sarath Publications by an authorized administrator of DigitalCommons@University of Nebraska - Lincoln. 


\title{
Modeling the tertiary structure of a maize (Zea mays ssp. mays) non-symbiotic hemoglobin
}

\author{
Juán Sáenz-Rivera ${ }^{\mathrm{a}}$, Gautam Sarath ${ }^{\mathrm{b}}$, Raúl Arredondo-Peter ${ }^{\mathrm{a}, *}$

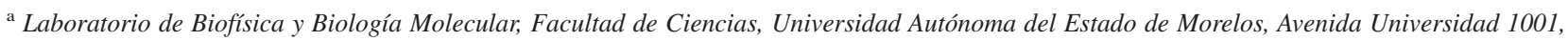 \\ Colonia Chamilpa, 62210 Cuernavaca, Morelos, Mexico \\ ${ }^{\mathrm{b}}$ USDA-ARS, Wheat, Sorghum and Forage Unit, Department of Agronomy and Horticulture, 332 Keim Hall, East Campus, University of \\ Nebraska-Lincoln, Lincoln, NE 68583-0939, USA
}

Received 10 April 2004; accepted 16 November 2004

Available online 21 December 2004

\begin{abstract}
The tertiary structure of a maize (Zea mays ssp. mays) non-symbiotic hemoglobin (Hbm) was modeled using computer tools and the known tertiary structure of rice $\mathrm{Hb} 1$ as a template. This method was tested by predicting the tertiary structure of soybean leghemoglobin a (Lba) using rice $\mathrm{Hb} 1$ as a template. The tertiary structures of the predicted and native Lba were similar, indicating that our computer methods could reliably predict the tertiary structures of plant Hbs. We next predicted the tertiary structure of Hbm. Hbm appears to have a long pre-helix A and a large CD-loop. The positions of the distal and proximal His are identical in Hbm and rice Hb1, which suggests that heme-Fe is hexacoordinate in $\mathrm{Hbm}$ and that the kinetic properties of $\mathrm{Hbm}$ and rice $\mathrm{Hb} 1$ are expected to be very similar, i.e. that $\mathrm{Hbm}$ has a high $\mathrm{O}_{2}$-affinity. Thermostability analysis showed that $\mathrm{Hbm} \mathrm{CD}$-loop is unstable and may provide mobility to amino acids located at the heme pocket for both ligand binding and stabilization and heme-Fe coordination. Analysis of the C-terminal half of Hbm showed the existence of a pocket-like region (the N/C cavity) where interactions with organic molecules or proteins could be possible. Lys K94 protrudes into the N/C cavity, suggesting that K94 may sense the binding of molecules to the N/C cavity. Thus, it is likely that the instability of the CD-loop and the possibility of binding molecules to the N/C cavity are essential for positioning amino acids in the heme pocket and in regulating Hbm activity and function.
\end{abstract}

(c) 2004 Elsevier SAS. All rights reserved.

Keywords: Hemoglobin; Non-symbiotic; Zea; Maize; Structure; Function

\section{Introduction}

Hemoglobins (Hbs) are ancient $\mathrm{O}_{2}$-binding proteins that have been identified in all kingdoms [27,29]. In plants, three types of Hbs have been identified: symbiotic, non-symbiotic (nsHbs) and truncated Hbs (tHbs) [22]. Symbiotic Hbs are synthesized in root nodules of nitrogen fixing plants, and their main function is to facilitate the diffusion of $\mathrm{O}_{2}$ to respiring bacteroids [1,2]. Plant tHbs are short versions of the classical globin fold. These proteins were recently detected in organs of angiosperm species, such as Arabidopsis [28], barley (Genbank accession number AF376063), maize (Genbank accession number AY104867) and wheat [18]. The function of plant tHbs is not known.

\footnotetext{
* Corresponding author. Tel.: +52 777329 7020; fax: +52 7773297040 .

E-mail address: ra@servm.fc.uaem.mx (R. Arredondo-Peter).
}

NsHbs have been detected in a number of land plants, ranging from primitive bryophytes [6] to angiosperms [4,22]. The $n s h b$ genes are expressed in plant embryonic and vegetative organs, and upregulation of $n s h b$ genes occurs in plants that are subjected to energetic stress, such as microaerobiosis and light limitation [19,24,26]. Although the function of nsHbs is still not known, recent work suggests that these proteins play important roles in plant metabolism. For example, it has been proposed that barley nsHb functions by modulating the energy status and NO-levels in transgenic maize cells [23] and stressed alfalfa root cultures [10], respectively.

A characteristic of nsHbs is a very high affinity for $\mathrm{O}_{2}$ because of an extraordinarily low $\mathrm{O}_{2}$-dissociation constant $\left(k^{\prime} \mathrm{O}_{2}\right)$. For example, the $k^{\prime} \mathrm{O}_{2}$ value for rice recombinant $\mathrm{Hb} 1$ is 316 -fold lower than the $k^{\prime} \mathrm{O}_{2}$ of sperm whale myoglobin $[4,5]$. This observation suggests that nsHbs do not release $\mathrm{O}_{2}$ after oxygenation, and that these proteins might not func- 
tion as $\mathrm{O}_{2}$-carriers. However, it has been hypothesized that nsHbs interact with regulatory molecules in plants [4]. A possible consequence of such interactions might be a change in the $\mathrm{nsHb}$ tertiary structure and kinetic constants, perhaps allowing nsHbs to function as $\mathrm{O}_{2}$-carriers or as $\mathrm{O}_{2}$-donors.

The best characterized nsHbs are rice $\mathrm{Hb} 1$ and barley $\mathrm{Hb}$ $[5,8,11,14,15]$; however, limited structural analysis has been performed on other plant nsHbs. In this work we have utilized computational methods to predict the tertiary structure of a $\mathrm{Hb}$ from maize ( $\mathrm{Hbm})$ [3]. Results showed that $\mathrm{Hbm}$ and rice $\mathrm{Hb} 1$ tertiary structures are almost identical, and suggest that $\mathrm{Hbm}$ is a high $\mathrm{O}_{2}$-affinity protein whose function might be modulated by binding of regulatory molecules.

\section{Results and discussion}

\subsection{Modeling and general features of $\mathrm{Hbm}$}

Despite the elucidation of the rice recombinant $\mathrm{Hb} 1$ crystal structure [14,15], only few analyses have been performed on the structure of other plant nsHbs. Although the function of nsHbs is not known, understanding the structural properties of nsHbs will help to clarify the role that these proteins play in plant organs. A maize $n s h b$ gene $(\mathrm{hbm})$ has been cloned and characterized [3]. The deduced $\mathrm{Hbm}$ amino acid sequence and hydropathy profiles were highly similar to rice Hb1 [3], suggesting that the two proteins should have similar crystal structures. In order to test this hypothesis, we have used computer tools and rice $\mathrm{Hb} 1$ as a template to predict a possible tertiary structure of Hbm. We have next used this model to discern potential properties of the Hbm molecule.

A Hbm tertiary structure was obtained by replacing the rice $\mathrm{Hb} 1$ primary sequence with the $\mathrm{Hbm}$ amino acid resi-

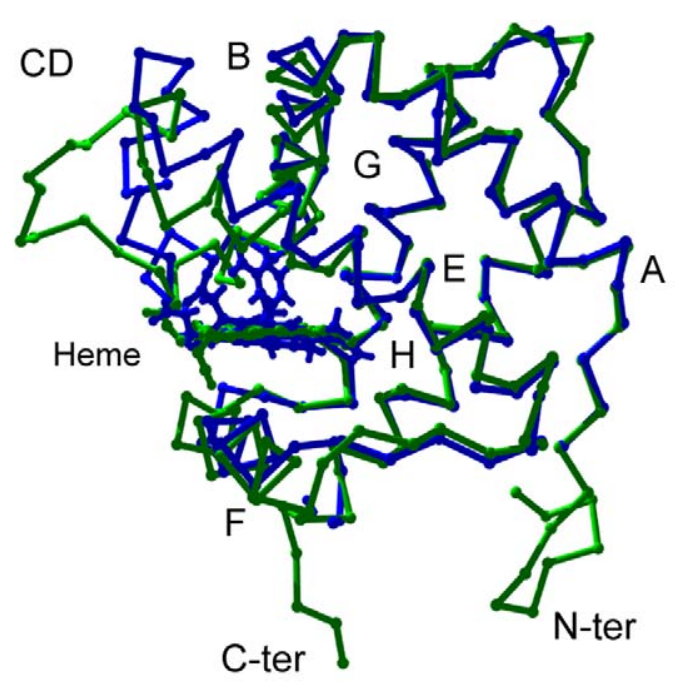

A dues using the MUTATE and CHARMM tools of the SwissPdbViewer program (see below). However, in order to test the reliability of this method, we first predicted a structure for soybean leghemoglobin a (Lba) using rice $\mathrm{Hb} 1$ as a template (Fig. 1A), and compared the resulting Lba structure with the native Lba crystal structure deposited in the Brookhaven Protein Data Base (http://www.rcsb.org/pdb, accession number 1FSL). Fig. 1B shows that the tertiary structures of predicted and native Lba are similar, indicating that the SwissPdbViewer program and the structure of template rice $\mathrm{Hb} 1$ are useful tools for predicting the tertiary structures of other plant Hbs.

Program Cn3D and MUTATE tool of SwissPdbViewer were used to align $\mathrm{Hbm}$ and rice $\mathrm{Hb} 1$ sequences, and to replace $\mathrm{Hbm}$ amino acids in the rice $\mathrm{Hb} 1$ structure, respectively. Thus, the initial structure for $\mathrm{Hbm}$ corresponded to a rice $\mathrm{Hb} 1$ structure with the $\mathrm{Hbm}$ amino acid sequence. The $\mathrm{Hbm}$ initial structure was used as template to predict a thermodynamically stable Hbm structure by using the CHARMM tool of SwissPdbViewer. The resulting structure showed that the Hbm tertiary structure is similar to that of rice $\mathrm{Hb} 1$ (Fig. 2). Like rice $\mathrm{Hb} 1, \mathrm{Hbm}$ has a long pre-helix A and large CD-loop. The positions of the distal and proximal His residues are identical in $\mathrm{Hbm}$ and rice $\mathrm{Hb} 1$, which suggests that in $\mathrm{Hbm}$ the heme-Fe is hexacoordinate (see below).

\subsection{Analysis of Hbm tertiary structure}

Thermostability analysis showed that the $\mathrm{N}$ - and C-termini and the $\mathrm{CD}$-loop regions of $\mathrm{Hbm}$ and rice $\mathrm{Hb} 1$ structures are relatively unstable thermodynamically (Fig. 3). This observation suggests that the instability of the $\mathrm{N}$ - and $\mathrm{C}$-termini and the CD-loop might provide high flexibility to the bottom and left side of $\mathrm{Hbm}$ and rice $\mathrm{Hb} 1$. The existence of instabil-

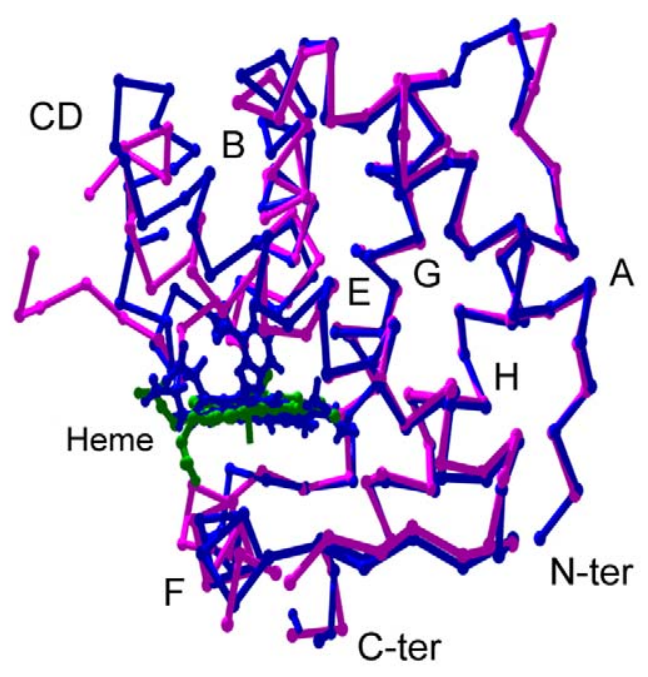

B

Fig. 1. (A) A predicted tertiary structure of soybean Lba (blue) from the rice Hb1 template (green). (B) Overlapped tertiary structure of the predicted (magenta) and native (blue) soybean Lba. Alpha helices are indicated with letters A-H. Ring structure above the heme corresponds to nicotinic acid. See Section 4 for experimental details. 


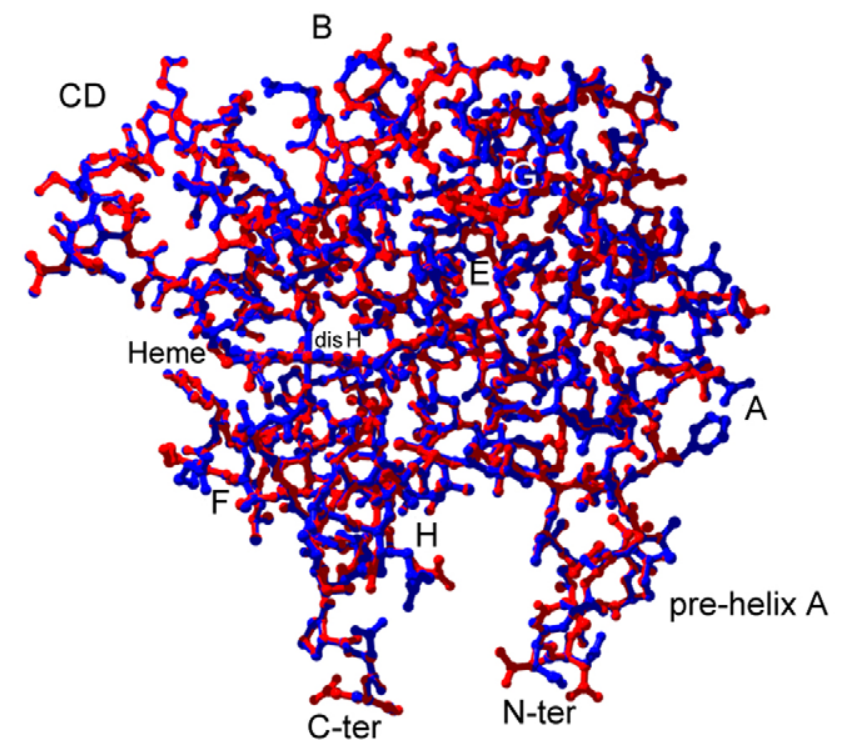

Fig. 2. Comparison of the predicted Hbm (blue) and rice Hb1 (red) tertiary structures. Tertiary structures are shown in the wireframe mode. Heme prosthetic group is shown from a side view. DisH above heme is distal His. Alpha helices are indicated with letters A-H. See Section 4 for experimental details.

ity in the $\mathrm{N}$ - and $\mathrm{C}$-termini and $\mathrm{CD}$-loop of $\mathrm{Hbm}$ and rice $\mathrm{Hb} 1$ could affect the function of these proteins.

Analysis of the heme pocket of $\mathrm{Hbm}$ and rice $\mathrm{Hb} 1$ showed that the key amino acid residues involved in ligand binding and stabilization, and in heme-Fe coordination are located at the same position and are in an identical orientation (Fig. 4). In both proteins, $\mathrm{N} \epsilon$ from the proximal and distal His residues are located $2.08 \AA$ from the heme-Fe. This observation shows that the proximal and distal His residues coordinate to the heme-Fe in Hbm. Also, FCD1 is located 5.02 $\AA$ from the heme-Fe and FCD1 and FB10 are located at the same distances from the distal $\mathrm{His} \mathrm{N} \epsilon$ in both $\mathrm{Hbm}$ and rice $\mathrm{Hb} 1$. Because of these observations, it is likely that kinetic prop-

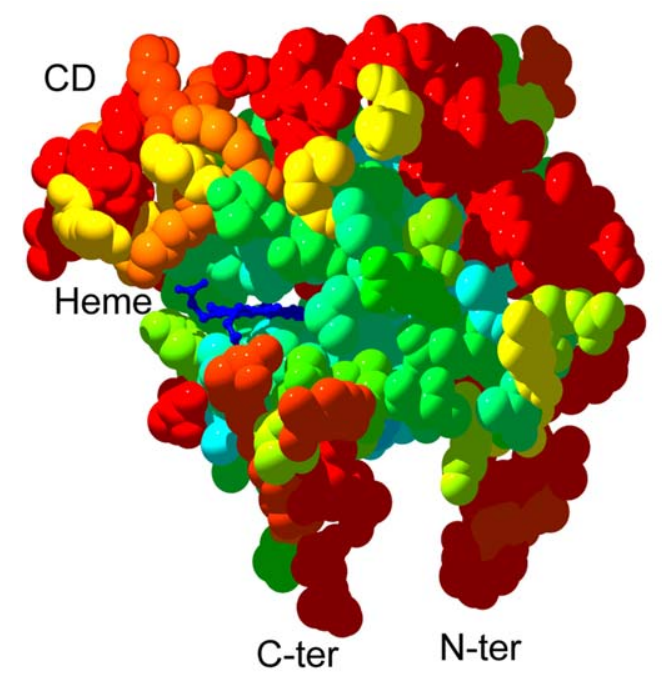

A

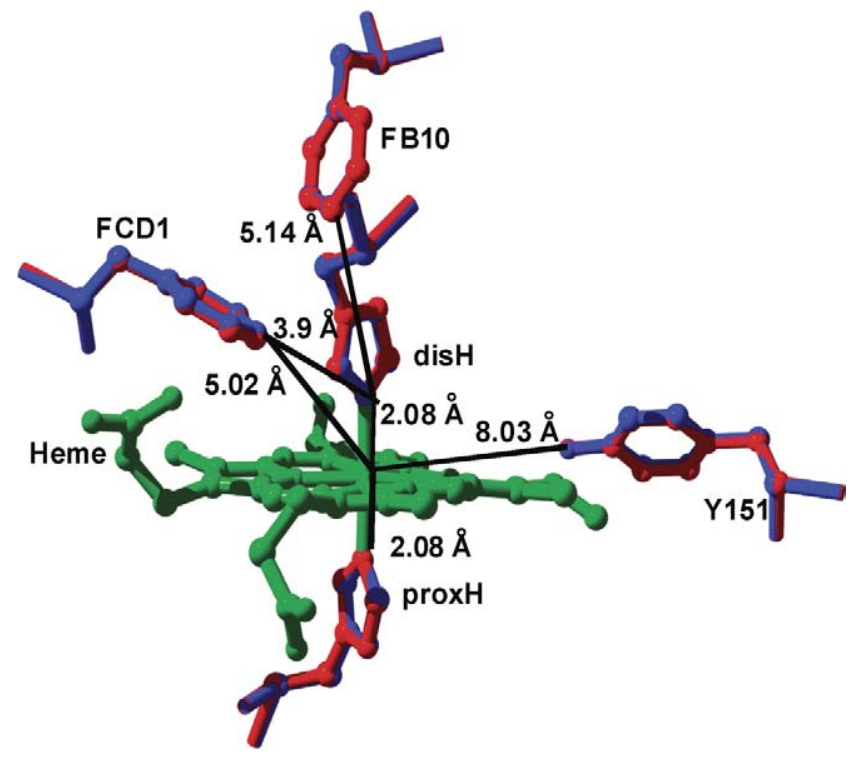

Fig. 4. Comparison of the orientation and position of selected amino acids in the $\mathrm{Hbm}$ (blue) and rice $\mathrm{Hb} 1$ (red) heme pocket. DisH and proxH are distal and proximal His, respectively. See text for a detailed explanation.

erties of $\mathrm{Hbm}$ and rice $\mathrm{Hb} 1$ are identical. The prediction is that $\mathrm{Hbm}$ has an extremely low $k^{\prime} \mathrm{O}_{2}$ constant because ligand stabilization by distal His, which results in a very high $\mathrm{O}_{2}$-affinity [5,14-16].

Ferric Hbs exhibit pseudoperoxidase activity. In the mechanism of this reaction, electrons are transferred from $\mathrm{Hbs}$ to $\mathrm{H}_{2} \mathrm{O}_{2}[13,20]$. During pseudoperoxidase reactions of Lbs one electron is transferred from an amino acid sidechain in the $\mathrm{Lb}$ heme pocket, generating a cation radical. EPR analysis showed that soybean Lba Y133 and lupin Lb Y138 are candidates for electron transfer [9]. Hbm Y151 is located at a similar distance and orientation from heme-Fe as soybean Lba Y133 and lupin Lb Y138 (Table 1, Fig. 4). This observation

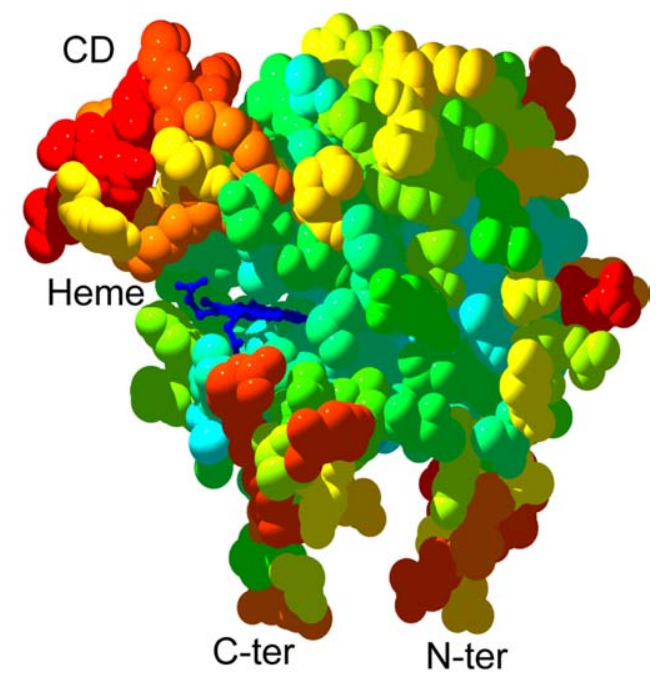

B

Fig. 3. Thermostability of $\mathrm{Hbm}$ (A) and rice $\mathrm{Hb} 1$ (B). Light blue to red colors show stable to unstable regions, respectively. Tertiary structures are shown in the spacefill mode. Heme prosthetic group is shown in dark blue color. See Section 4 for experimental details. 
Table 1

Tyrosine (Y151/133/138) orientation in the Hbm and soybean and lupin Lbs heme pocket

\begin{tabular}{|c|c|c|c|c|}
\hline \multirow[t]{2}{*}{ Tyrosine $(\mathrm{Y})$ residue } & \multicolumn{3}{|c|}{ Orientation $^{\mathrm{a}}$} & \multirow{2}{*}{$\begin{array}{l}\mathrm{Fe}-\mathrm{Y}(\mathrm{OH}) \\
\text { distance }(\AA)\end{array}$} \\
\hline & $\omega\left(^{\circ}\right)$ & $\varphi\left(^{\circ}\right)$ & $\phi\left(^{\circ}\right)$ & \\
\hline Hbm Y151 & -177.17 & -59.59 & -53.94 & 8.03 \\
\hline Soybean Lb Y133 ${ }^{\mathrm{b}}$ & -179.61 & -67.17 & -54.04 & 8.38 \\
\hline Lupin Lb Y $138^{\mathrm{b}}$ & +178.39 & -58.93 & -54.00 & 8.57 \\
\hline
\end{tabular}

${ }^{\mathrm{a}}$ Omega $(\omega)$, phi $(\varphi)$ and psi $(\phi)$ are dihedral angles of picked tyrosine.

${ }^{\mathrm{b}} \mathrm{Y} 133$ and Y138 coordinates were obtained from soybean and lupin Lb structures with the accession numbers $\underline{1 F S L}$ and $\underline{\text { 2LH6}}$, respectively.

suggests that Hbm Y151 might function in electron transfer, and that Hbm is likely to possess peroxidative activity.

The lengths of $\mathrm{Hbm}$ and rice $\mathrm{Hb} 1 \mathrm{CD}$-loops are similar to that from several plant and non-plant Hbs. However, the Hbm and rice $\mathrm{Hb} 1 \mathrm{CD}-$ loops are unique in that they are extended, poorly ordered and oriented outward (Fig. 5, upper panel). Thermostability analysis showed that the $\mathrm{Hbm}$ and rice Hb1 CD-loops are unstable and flexible (Fig. 3, above). The apparent instability of the $\mathrm{CD}$-loop in $\mathrm{Hbm}$ and rice $\mathrm{Hb} 1$ may provide mobility to helix E, resulting in positioning the distal His closer to the heme-Fe for hexacoordination and ligand stabilization [15]. We tested this possibility by displacing the Hbm CD-loop $0.5 \AA$ upward and downward. Results showed that the position of the distal and proximal His, FB10, FCD1 and Y151 changed with the CD-loop movement (Fig. 5, lower panel). This observation suggests that the mobility of CD-loop affects the positioning of amino acids located at the heme pocket for both ligand binding and stabilization and heme-Fe coordination. For example, it has been hypothesized that the distal His dissociates from the heme-Fe in hexacoordinate $\mathrm{Hbs}$ before $\mathrm{O}_{2}$ can bind, and then moves back to

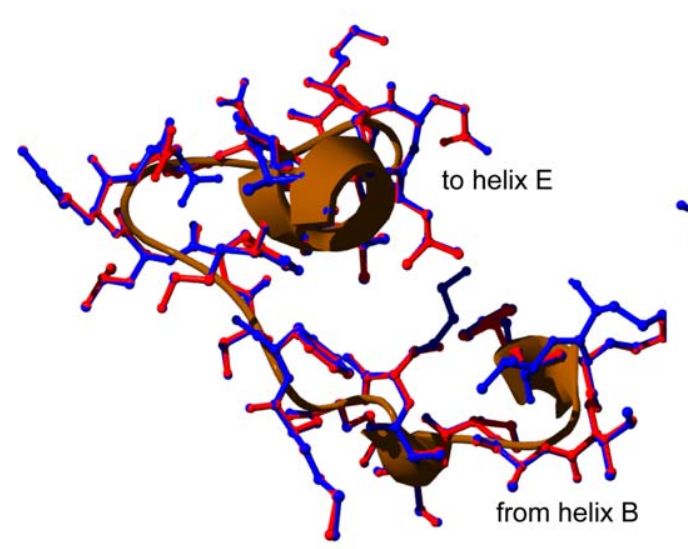

A

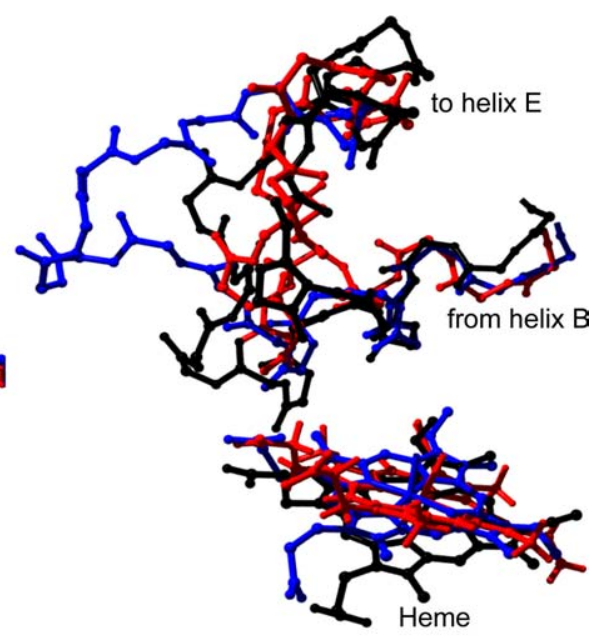

B

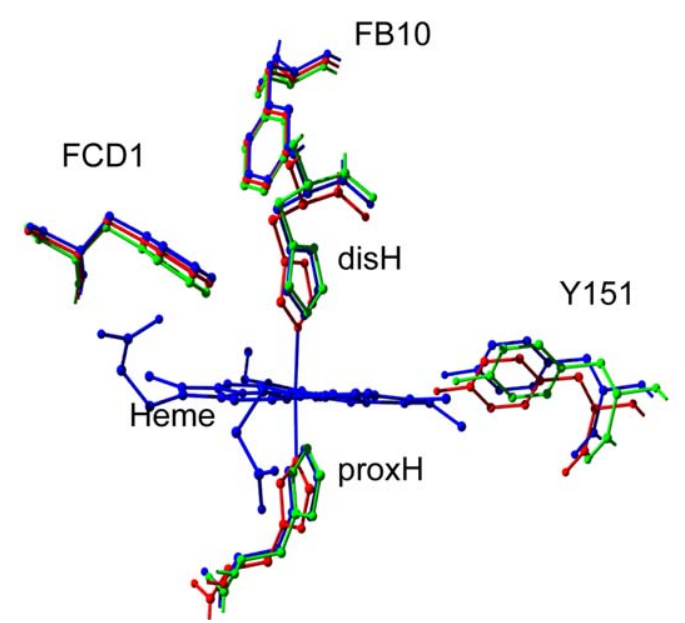

Fig. 5. Upper panel: comparison of (A) Hbm (blue) and rice Hb1 (red) CD-loops, and (B) Hbm (blue) and soybean Lba (red) CD-loops and sperm whale myoglobin helices $\mathrm{C}$ and D (black). Lower panel: positions of disH, proxH, FB10, FCD1 and Y151 after displacing the Hbm CD-loop $0.5 \AA$ A upward (green) or downward (red). Amino acids in blue color show positions before CD-loop movement. 


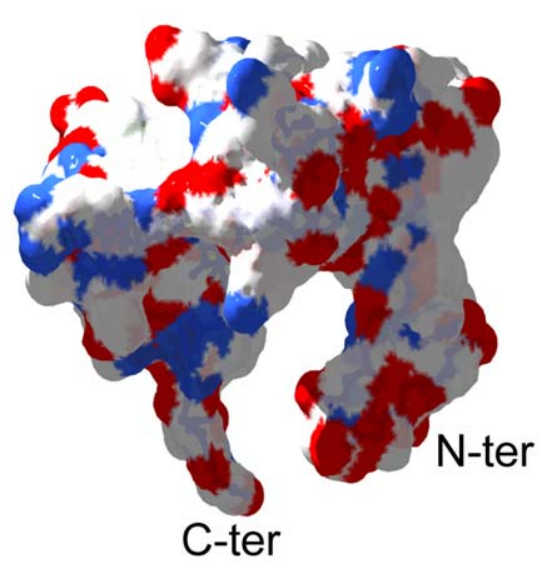

A

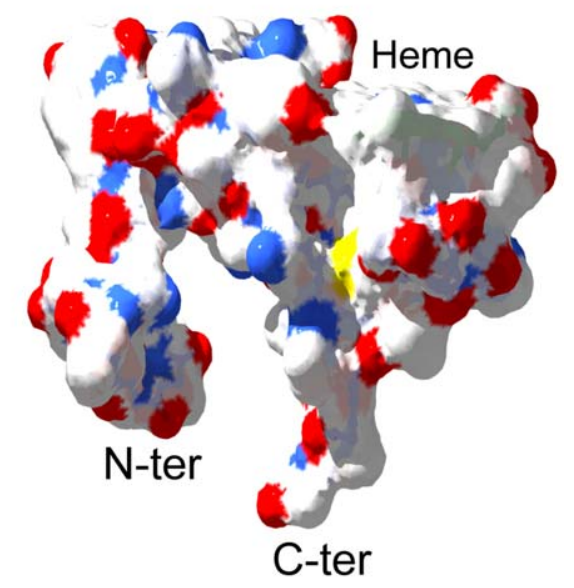

B

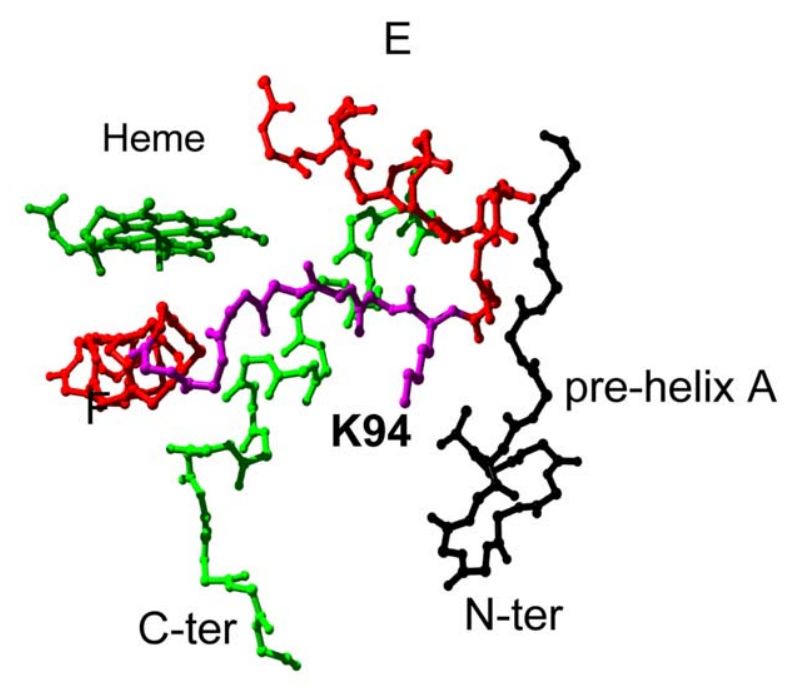

C

Fig. 6. Front (A) and back (B) views of Hbm C-terminal half showing the N/C cavity formed by N- and C-termini and helices A, F and H. Blue and red colors show positively or negatively charged amino acids, respectively. (C) Location of Lys K94 in the EF turn indicates that it can protrude into the N/C cavity.

stabilize the bound $\mathrm{O}_{2}[16,25]$. Thus, it is likely that instability of CD-loop is critical in $\mathrm{Hbm}$ and rice $\mathrm{Hb} 1$ for regulating an open $\leftrightarrows$ closed conformation mechanism for ligand (i.e. $\mathrm{O}_{2}$ )-affinity.

Analysis of the C-terminal half of Hbm showed that the pre-helix A, helices $\mathrm{A}, \mathrm{F}$ and $\mathrm{H}$ and the $\mathrm{C}$-terminus form a pocket-like region (the N/C cavity) (Fig. 6A, B). Topology of the N/C cavity suggests that either organic molecules or protein-partners could interact with this region. Interaction of Hbs with small molecules is well documented [7,21], and it has also been suggested that interactions of nsHbs with cellular metabolites could impact their function [4]. Thus, a possibility is that the N/C cavity is a region where Hbm interacts with small molecules. An interesting observation is that Lys $\mathrm{K} 94$ (which is located at the EF turn) protrudes into the N/C cavity (Fig. 6C), which suggests that K94 may function as a trigger if molecules accommodate into the N/C cavity. If this is true, K94 might sense binding of molecules to the N/C cavity and transmit a signal to helices $\mathrm{E}$ and $\mathrm{F}$, where distal and proximal His are located, respectively. This (K94) mechanism may help to modulate $\mathrm{Hbm}$ kinetics and function in the plant cell.

\section{Conclusions}

Analysis of the predicted structure of $\mathrm{Hbm}$ shows that $\mathrm{Hbm}$ and rice $\mathrm{Hb} 1$ tertiary structures are similar and suggests that the biochemical properties of both proteins are the same, i.e. $\mathrm{Hbm}$ is a hexacoordinate $\mathrm{Hb}$ with a very high affinity for $\mathrm{O}_{2}$ because an extraordinarily low $k^{\prime} \mathrm{O}_{2}$. Also, analyses from this work predict that $\mathrm{Hbm}$ is a flexible protein, whose activity (and function) is modulated through changes in the positions of amino acid sidechains that are essential for ligand binding and stabilization, such as the distal His, FB10 and FCD1. It is likely that CD-loop instability and the possibility of binding 
molecules to the N/C cavity could affect the positions of amino acids in the distal region of the heme pocket, and thereby regulate $\mathrm{Hbm}$ activity and function in plant cells.

\section{Methods}

Prediction of tertiary structure, modeling and analysis of $\mathrm{Hbm}$ were performed by using the computer programs SwissPdbViewer and Cn3D. These programs are available from the web sites http://www.expasy.ch/spdbv/ and http://www.ncbi.nlm.nih.gov/Structure/CN3D/cn3d.shtml, respectively.

\subsection{Prediction and modeling of the Hbm tertiary structure}

The Hbm amino acid sequence [3] and rice $\mathrm{Hb} 1$ tertiary structure [15] were obtained from the GenBank database (http://www.ncbi.nlm.nih.gov/GenBank/index) using the accession numbers AAG01375 and 1D8U, respectively. Hbm and rice $\mathrm{Hb} 1$ sequences were aligned by using the $\mathrm{Cn} 3 \mathrm{D}$ program. The first version of the $\mathrm{Hbm}$ tertiary structure was obtained by replacing amino acids from the $\mathrm{Hbm}$ sequence into the rice $\mathrm{Hb} 1$ sequence and tertiary structure by using the MUTATE tool of SwissPdbViewer program. The final version of the $\mathrm{Hbm}$ tertiary structure was obtained by using the CHARMM tool of SwissPdbViewer program, which predicted a thermodynamically stable conformation for the $\mathrm{Hbm}$ model.

In order to test the reliability of the above method, the tertiary structure of soybean Lba was predicted by using rice $\mathrm{Hb} 1$ structure as template. The resulting Lba model was compared with the Lba tertiary structure [12,17] deposited in the Brookhaven Protein Data Base (http://www.rcsb.org/pdb) under the accession number 1FSL.

\subsection{Analysis of Hbm tertiary structure}

The predicted $\mathrm{Hbm}$ tertiary structure was analyzed by using tools from the SwissPdbViewer program. Specific regions of predicted $\mathrm{Hbm}$ were selected with the SHOW tool. Amino acid residues that form the heme pocket, pre-helix A and helices $\mathrm{F}$ and $\mathrm{H}$ were selected with the DISPLAY RADIUS tool. Surface areas were selected with the COMPUTE MOLECULAR SURFACE tool. Charge distribution and temperature factors were calculated with the COLOR TYPE and COLOR B-FACTOR tools, respectively. Existence of hydrogen bonds and electrostatic potentials were predicted and calculated with the COMPUTE H-BONDS and COMPUTE ELECTROSTATIC POTENTIAL tools, respectively. Exposure of amino acid residues from the $\mathrm{Hbm}$ structure was calculated with the ACCESIBLE AA tool. Distances between atoms, amino acid orientation and torsion angles were calculated by using options from the program's main menu.

\section{Acknowledgements}

This work was partially funded by Consejo Nacional de Ciencia y Tecnología (project numbers 25229-N and 42873-
Q), DGAPA-PAPIIT/UNAM (project number IN202399) and PROMEP (project number UAEMor-PTC-01-01/PTC-23), México; and by 1 P20 RR 16469 from BRIN Program of the National Center for Research Resources, USA.

\section{References}

[1] C.A. Appleby, Leghemoglobin and Rhizobium respiration, Annu. Rev. Plant Physiol. 35 (1984) 443-478.

[2] C.A. Appleby, The origin and functions of haemoglobin in plants, Sci. Prog. 76 (1992) 365-398.

[3] E. Aréchaga-Ocampo, J. Sáenz-Rivera, G. Sarath, R.V. Klucas, R. Arredondo-Peter, Cloning and expression analysis of hemoglobin genes from maize (Zea mays ssp. mays) and teosinte (Zea mays ssp. parviglumis, Biochim. Biophys. Acta 1522 (2001) 1-8.

[4] R. Arredondo-Peter, M.S. Hargrove, J.F. Moran, G. Sarath, R.V. Klucas, Plant hemoglobins, Plant Physiol. 118 (1998) 1121-1126.

[5] R. Arredondo-Peter, M.S. Hargrove, G. Sarath, J.F. Moran, J. Lohrman, J.S. Olson, et al., Rice hemoglobins: gene cloning, analysis and oxygen-binding kinetics of a recombinant protein synthesized in Escherichia coli, Plant Physiol. 115 (1997) 1259-1266.

[6] R. Arredondo-Peter, M. Ramírez, G. Sarath, R.V. Klucas, Sequence analysis of an ancient hemoglobin cDNA isolated from the moss Physcomitrella patens (Accession No. AF218049), Plant Physiol. 122 (2000) 1457.

[7] A. Bonamore, A. Farina, M. Gattoni, M.E. Schinina, A. Bellelli, A. Boffi, Interaction with membrane lipids and heme ligand binding properties of Escherichia coli flavohemoglobin, Biochemistry 42 (2003) 5792-5801.

[8] T.K. Das, H.C. Lee, S.M.G. Duff, R.D. Hill, J. Peisach, D.L. Rousseau, et al., The heme environment in barley hemoglobin, J. Biol. Chem. 274 (1999) 4207-4212.

[9] M.J. Davies, C. Mathieu, A. Puppo, Leghemoglobin: properties and reactions, Adv. Inorg. Chem. 46 (1999) 495-542.

[10] C. Dordas, B.B. Hasinoff, A.U. Igamberdiev, N. Manasch, J. Rivoal, R.D. Hill, Expression of a stress-induced hemoglobin affects NO levels produced by alfalfa root cultures under hypoxic stress, Plant J. 35 (2003) 763-770.

[11] S.M.G. Duff, J.B. Wittenberg, R.D. Hill, Expression, purification and properties of recombinant barley (Hordeum sp.) hemoglobin: optical spectra and reactions with gaseous ligands, J. Biol. Chem. 272 (1997) 16746-16752.

[12] P.J. Ellis, C.A. Appleby, J.M. Guss, W.N. Hunter, D.L. Ollis, H.C. Freeman, Structure of ferric soybean leghemoglobin $a$ nicotinate at $2.3 \AA$ resolution, Acta Crystallogr. 53 (1997) 302-310.

[13] R.E. Glover, V. Koshkin, H.B. Dunford, R.P. Mason, The reaction rates of NO with horseradish peroxidase compounds I and II, Nitric Oxide: Biol. Chem. 3 (1999) 439-444.

[14] M.D. Goodman, M.S. Hargrove, Quaternary structure of rice nonsymbiotic hemoglobin, J. Biol. Chem. 276 (2001) 6834-6839.

[15] M.S. Hargrove, E.A. Brucker, B. Stec, G. Sarath, R. Arredondo-Peter, R.V. Klucas, J.S. Olson, G.N. Philips Jr., Crystal structure of a nonsymbiotic hemoglobin, Structure 8 (2000) 1005-1014.

[16] M.S. Hargrove, A flash photolysis method to characterize hexacoordinate hemoglobin kinetics, Biophys. J. 79 (2000) 2733-2738.

[17] M.S. Hargrove, J.K. Barry, E.A. Brucker, M.B. Berry, G.N. Phillips, J.S. Olson, et al., Characterization of recombinant soybean leghemoglobin a and apolar distal histidine mutants, J. Mol. Biol. 267 (1997) 1032-1042.

[18] K. Larsen, Molecular cloning and characterization of cDNAs encoding hemoglobin from wheat (Triticum aestivum) and potato (Solanum tuberosum), Biochim. Biophys. Acta 1621 (2003) 299-305.

[19] V. Lira-Ruan, G. Sarath, R.V. Klucas, R. Arredondo-Peter, Synthesis of hemoglobins in rice (Oryza sativa var. Jackson) plants growing in normal and stress conditions, Plant Sci. 161 (2001) 279-287. 
[20] P.I. Ohlsson, K.C. Paul, The molar absorptivity of horseradish peroxidase, Acta Chem. Scand. A 30 (1976) 373-375.

[21] G. Ollesch, A. Kaunzinger, D. Juchelka, M. Schubert-Zsilavecz, U. Ermler, Phospholipid bound to the flavohemoprotein from Alcaligenes eutrophus, Eur. J. Biochem. 262 (1999) 396-405.

[22] E.J.H. Ross, V. Lira-Ruan, R. Arredondo-Peter, R.V. Klucas, G. Sarath, Recent insights into plant hemoglobins, Rev. Plant Biochem. Biotechnol. 1 (2002) 173-189.

[23] A.W. Sowa, S.M.G. Duff, P.A. Guy, R.D. Hill, Altering hemoglobin levels changes energy status in maize cells under hypoxia, Proc. Natl. Acad. Sci. USA 95 (1998) 10317-10321.

[24] E.R. Taylor, X.Z. Nie, A.W. MacGregor, R.D. Hill, A cereal haemoglobin gene is expressed in seed and root tissues under anaerobic conditions, Plant Mol. Biol. 24 (1994) 853-862.
[25] J.T. Trent III, A.N. Hvitved, M.S. Hargrove, A model for ligand binding to hexacoordinate hemoglobins, Biochemistry 40 (2001) 6155-6163.

[26] B. Trevaskis, R.A. Watts, S.R. Andersson, D.J. Llewellyn, M.S. Hargrove, J.S. Olson, et al., Two hemoglobin genes in Arabidopsis thaliana: the evolutionary origins of leghemoglobins, Proc. Natl. Acad. Sci. USA 94 (1997) 12230-12234.

[27] S.N. Vinogradov, D.A. Waltz, B. Pohajdak, L. Moens, O.H. Kapp, T. Suzuki, et al., Adventitious variability? The amino acid sequences of nonvertebrate globins, Comp. Biochem. Physiol. 106B (1993) $1-26$.

[28] R.A. Watts, P.W. Hunt, A.N. Hvitved, M.S. Hargrove, W.J. Peacock, E.S. Dennis, A hemoglobin from plants homologous to truncated hemoglobins of microorganisms, Proc. Natl. Acad. Sci. USA. 98 (2001) 10119-10124.

[29] R. Weber, S.N. Vinogradov, Nonvertebrate hemoglobins: functions and molecular adaptations, Physiol. Rev. 81 (2001) 569-628. 